\title{
Restricted movement by mottled sculpin (pisces: cottidae) in a southern Appalachian stream
}

\author{
J. TODD PETTY AND GARY D. GROSSMAN \\ D.B. Warnell School of Forest Resources, University of Georgia, Athens, GA, U.S.A.
}

\section{SUMMARY}

1. We used direct observation and mark-recapture techniques to quantify movements by mottled sculpins (Cottus bairdi) in a $1 \mathrm{~km}$ segment of Shope Fork in western North Carolina. Our objectives were to: (i) quantify the overall rate of sculpin movement, (ii) assess variation in movement among years, individuals, and sculpin size classes, (iii) relate movement to variation in stream flow and population size structure, and (iv) quantify relationships between movement and individual growth rates.

2. Movements were very restricted: median and mean movement distances for all sculpin size classes over a 45 day period were 1.3 and $4.4 \mathrm{~m}$ respectively. Nevertheless, there was a high degree of intrapopulation and temporal variation in sculpin movement. Movement of juveniles increased with discharge and with the density of large adults. Movement by small and large adults was not influenced by stream flow, but large adults where more mobile when their own density was high. Finally, there were differences in the growth rates of mobile and sedentary sculpins. Mobile juveniles grew faster than sedentary individuals under conditions of low flow and high density of large adults, whereas adults exhibited the opposite pattern.

3. Our results support the hypothesis that juvenile movement and growth is influenced by both intraspecific interactions with adults and stream flow. In contrast, adult movement appears to be influenced by competitive interactions among residents for suitable space. The relationship between movement and growth may provide a negative feedback mechanism regulating mottled sculpin populations in this system.

Keywords: flow variability, growth, restricted movement, size-dependent interactions, stream fish

\section{Introduction}

Animal movement is a key mechanism underlying a host of ecological processes, including habitat selection (Brown, 1988; Hughes, 1998), population dynamics (Kareiva, 1990), predator-prey interactions (Stewart-Oaten \& Murdoch, 1990), and community structure (Tilman, 1994). This is particularly true for stream fishes, which inhabit spatially and temporally complex environments (Hildrew \& Giller, 1994). Stream fishes require access to a wide array of habitat types for feeding and reproduction, and also access to

Correspondence: J. Todd Petty, Division of Forestry,

West Virginia University, Morgantown, WV 26506, U.S.A.

E-mail: jtpetty@wvu.edu

(C) 2004 Blackwell Publishing Ltd refuges from predators and environmental extremes (Schlosser, 1995). Depending on the spatial arrangement of habitat patches in the landscape, fishes may be required to move long distances to find scarce or critical resources. Consequently, movement controls a variety of ecological patterns in stream fishes, such as longitudinal size patterns (Hughes \& Reynolds, 1994; Hughes, 1998), source-sink dynamics (Schlosser, 1998), colonisation of newly available habitats (Taylor, 1997; Lonzarich, Warren \& Lonzarich, 1998), and fish assemblage structure (Osborne \& Wiley, 1992; Snodgrass \& Meffe, 1998).

Because of its importance to stream fish ecology, researchers have produced a substantial body of work on fish movement (see Gowan et al., 1994; Matthews, 1998; Rodríguez, 2002 for reviews). Generally, these 
studies have focused on fish movement rates along stream corridors and simply addressed whether fishes are sedentary or mobile (Gowan et al., 1994; Fausch \& Young, 1995). The traditional view of stream fish movement, referred to by Gowan et al. (1994) as the 'Restricted Movement Paradigm' (henceforth RMP), maintains that adult fishes are sedentary, often spending their entire lives within the same channel unit or stream reach (Gerking, 1953). Subsequent field studies of fish movement tended to support the view of restricted movement by fishes, with the exception of highly migratory species.

More recent findings indicate that the simplistic view that all stream fishes are sedentary is incorrect (Gowan et al., 1994; Skalski \& Gilliam, 2000; Gilliam \& Fraser, 2001; Rodríguez, 2002). In fact, Gowan et al. (1994) argued that stream salmonids are mobile, rather than sedentary, and that support for the RMP was largely the result of flawed study designs and misinterpretation of data by previous authors. Subsequent analyses of salmonid movement data by Rodríguez (2002) tempered this view slightly, but also clearly affirmed a high degree of variability in the range of movements exhibited by stream salmonids. Researchers also continue to discover that fish movement behaviour is affected by a variety of factors including: species, time of year, fish age/size, and local environmental conditions (Matthews, 1998).

Despite recent advances in the study of fish movements, two important information gaps remain. First, we know very little about the mobility of non-game fishes, especially benthic species. Besides some notable exceptions (Hill \& Grossman, 1987a; Freeman, 1995; Matheney \& Rabeni, 1995; Lonzarich, Lonzarich \& Warren, 2000; Skalski \& Gilliam, 2000; Gilliam \& Fraser, 2001), most data on stream fish movements are based on studies of salmonids or centrarchids (Todd \& Rabeni, 1989; Gatz \& Adams, 1994; Gowan et al., 1994; Rodríguez, 2002). This is unfortunate given that cyprinids and benthic species dominate fish assemblages in most north temperate streams (Lee, Gilbert $\&$ et al., 1980). Furthermore, these species possess lifehistory requirements that are very different from most trout species (Jenkins \& Burkhead, 1994). Consequently, it is difficult to infer general patterns and causes of movement by stream fish communities solely from information on stream-dwelling salmonids.
Secondly, the underlying mechanisms that cause animals to move are poorly understood (Turchin, 1998). Potential determinants of fish movement in streams include variation in stream flow and temperature, changes in habitat quality and the distribution of habitat patches, and seasonal changes in habitat requirements. Additional ecological determinants include intra- and inter-specific interactions, such as competition and predation (Nakano, 1995; Gilliam \& Fraser, 2001). Despite this extensive list of potential mechanisms, researchers have largely ignored questions regarding the causes and consequences of movement by stream fishes.

To address gaps in our understanding of stream fish movement, we conducted a long-term descriptive study of mottled sculpin (Cottus bairdi, Girard). Sculpins are widely distributed across North America and frequently dominate stream fish assemblages in both abundance and biomass (see references in Grossman, McDaniel \& Ratajczak, 2002). In the Coweeta Creek basin of western North Carolina, sculpins are sit-and-wait predators that select microhabitats comprised of coarse substrata and feed primarily on benthic macroinvertebrates (Stouder, 1990; Petty \& Grossman, 1996; Grossman \& Ratajczak, 1998). They can live to age 7, grow slowly, and have low fecundity (maximum fecundity <250 eggs) (Grossman et al., 2002).

Recent studies in the Coweeta Creek drainage indicate that sculpin populations are influenced by three factors. First, Petty \& Grossman (1996) found that sculpin distributions are controlled by the patchy distribution of suitable habitat and food. Adults are able to identify patches of high invertebrate density and select microhabitats that maximise their access to food (Petty \& Grossman, 1996). Secondly, a 12-year study of sculpin populations established that temporal variation in population density and age structure is primarily influenced by density-dependent interactions between adults and juveniles (G. D. Grossman et al., unpublished data), with flow variation playing a secondary role. Finally, size-dependent interactions among residents may influence the distribution and habitat use of small adult and juvenile sculpins (Freeman \& Stouder, 1989). Freeman \& Stouder (1989) found that large adults (i.e. sculpins $>65 \mathrm{~mm}$ ) caused small individuals to shift from deeper, centrally located microhabitats to shallow water along the stream margin. The authors attribute this response to c 2004 Blackwell Publishing Ltd, Freshwater Biology, 49, 631-645 
the ability of large dominant adults to exclude small individuals from high quality patches. The manner in which each of these factors influences movement is currently unknown.

To ascertain how abiotic and biotic factors may affect sculpin movement and to determine the relevance of the RMP to this population, we addressed four objectives. First, we quantified the extent and rate of movement by sculpins in a $1-\mathrm{km}$ section of Shope Fork. Secondly, we examined intrapopulation variation (among individuals and size classes) in sculpin movement. Thirdly, we quantified temporal variation in sculpin movement and compared this variation to hydrologic conditions and population size structure. Fourthly, we described the relationship between movement behaviour and individual fitness (i.e. growth rate) of sculpins under different conditions of stream flow and population structure.

\section{Methods}

The study site and sampling regime

Shope Fork is a fourth order tributary of Coweeta Creek, which is located on the USDA Coweeta Hydrologic Laboratory in western North Carolina, U.S.A. Shope Fork is a relatively undisturbed, coldwater stream (maximum summer temperature $<20^{\circ} \mathrm{C}$ ), and is representative of many small streams in this region. The stream lies within a mixed hardwood-conifer forest with an understory of rhododendron (Rhododendron maximum L.), mountain laurel (Kalmia latifolia L.) and dogwood (Cornus florida L.). At its mouth, Shope Fork is just under $700 \mathrm{~m}$ in altitude, drains a 2185 ha catchment, and has a longterm, annual mean discharge of $0.23 \mathrm{~m}^{3} \mathrm{~s}^{-1}$. Typical of small, Appalachian streams, the lower Shope Fork fish assemblage includes just four species: mottled sculpin, rainbow trout (Oncorhynchus mykiss Walbaum), longnose dace (Rhinichthys cataractae Valenciennes), and rosyside dace (Clinostomus funduloides Girard).

We observed fish while snorkeling and used markrecapture techniques to quantify sculpin movements and estimate demographic parameters. We used the 'Robust' mark-recapture sampling design of Pollock et al. (1990), which consisted of sampling at both primary and secondary time scales. A primary sample was a single seasonal sample taken in a single year.
We completed four primary samples [spring/early summer (early June), mid summer (late July), late summer (early September), and autumn (late October)l in each of 3 years (1994-96). Secondary samples consisted of four separate sampling passes made over a 7-10 day period within each primary sample, which yielded a total of 16 sampling passes made each year. Passes made within each season were separated by 12 days, and each seasonal sample was separated by approximately 45 days. We assumed that the population was closed within primary samples and open between them (Pollock et al., 1990).

Intensive sampling of sculpin populations was confined to a central $200 \mathrm{~m}$ core of the $1-\mathrm{km}$ site on Shope Fork. Each time a sampling pass was conducted, we observed sculpins within the $200 \mathrm{~m}$ core (i.e. four passes per season within the core). We also sampled two $400 \mathrm{~m}$ 'buffer zones' located immediately up- and downstream of the study core at the end of each season (i.e. one pass per season within the buffer zones). Buffer zones were sampled to capture marked individuals that may have moved out of the core site. Our study design ensured that we were able to characterise small and large-scale movements.

However, the unbalanced nature of our sampling design inserts an unfortunate bias into our analyses of movement. Specifically, we were more likely to observe short movements than long movements, because sampling within the core area was four times more frequent than sampling in the buffer zones. Nevertheless, we do not believe that this sampling discrepancy affects our overall findings for two reasons. First, over $75 \%$ of the sculpins originally marked in our study were recaptured and, of these recaptures, $<2 \%$ occurred outside of the core (see Results). Secondly, of the individuals captured outside of the core, none was further than $50 \mathrm{~m}$ from the core border (see Results). These findings suggest that both our sampling area and design were adequate for the detection of potential large-scale movements by this species.

\section{Field observations}

We began each sampling pass by entering the $200 \mathrm{~m}$ core site at a randomly determined location and snorkeling slowly upstream. Regardless of where we entered, we covered the entire $200 \mathrm{~m}$ core area in a 
single day. On the fourth pass of each season, we covered the entire $1 \mathrm{~km}$ site. This final pass usually took 2-3 days to complete. When we located a sculpin we immediately captured it with a dip net and marked its focal position with a painted lead weight. At the time of first capture, individuals were lightly anaesthetised with MS222 and marked with acrylic paints injected subcutaneously (Hill \& Grossman, 1987b). Use of four colours (blue, green, red and yellow) and six body locations (four along the anal fin and one at the base of each pectoral fin) ensured that each individual could be uniquely marked. An instream, double marking study, using fin clips and acrylic paints, indicated that mark retention by juveniles and adults was extremely high (i.e. $>90 \%$ ) for up to 16 months and did not differ significantly among size classes (J. T. Petty \& G. D. Grossman, unpublished data). Newly marked and recaptured individuals were weighed with an electronic balance $( \pm 0.05 \mathrm{~g})$ and measured (standard length, $\pm 1 \mathrm{~mm}$ ), allowed to revive in fresh water, and returned to their exact location of capture. After snorkeling the entire $200 \mathrm{~m}$ core site, we triangulated the exact location $( \pm 5 \mathrm{~cm})$ of each captured individual via a mapped network of permanent transect posts positioned along the stream margin.

Because we were interested in examining sizedependent variation in sculpin behaviour, we used length measurements to classify captured individuals into one of three size classes: juveniles (SL $\leq 48 \mathrm{~mm}$ ), small adults $(48<\mathrm{SL}<65 \mathrm{~mm}$ ), and large adults $(\geq 65 \mathrm{~mm})$. Demographic studies of sculpins in the Coweeta Creek drainage demonstrate that juveniles can be clearly separated from adults on the basis of standard length (Petty, 1998). However, there is considerable overlap in the body size of adult sculpins of different ages (Grossman et al., 2002). Nonetheless, our previous studies have shown that size affects a variety of ecological characteristics of sculpins (Grossman \& Freeman, 1987; Grossman \& Ratajczak, 1998; Grossman et al., 2002) and consequently warrants consideration in this study.

We monitored stream discharge in Shope Fork from gauge height data obtained from a US Forest Service gauging station located immediately upstream of the study site. The study period included an extremely wet year (1994), an extremely dry year (1995), and one of moderate flow (1996).
Analysis of sculpin demography and stream flow

We used mark-recapture data to calculate site residency rates, sculpin population size and population size-structure. We calculated site residency rates as the proportion of individuals captured within the $200 \mathrm{~m}$ core site in at least two separate seasonal samples (i.e. proportion residing in the core site $>45$ days). Site residency rates were calculated separately for each size class each year and compared using log-likelihood goodness-of-fit tests. We used the program CAPTURE to estimate population size for each size class during each season and also calculated variation in population size structure from these estimates. Finally, we used Kolmogrov-Smirnov tests for continuous data to test for significant differences in stream discharge among the 3 years of the study.

\section{Analysis of sculpin movement}

We quantified sculpin movements by recording the $x$, $y$ coordinates of each sequential capture of an individual within a given year. Our general design followed Turchin (1998), and we assigned positive values to upstream moves and negative values to downstream moves. Because movement distances within a year were not significantly correlated with time elapsed between recaptures $\left(R^{2}\right.$ ranged from $0.001-0.003)$, we quantified movement in units of linear distance (i.e. metres) rather than as a rate (e.g. $\mathrm{m} \mathrm{day}^{-1}$ ) (Turchin, 1998). We then constructed twotailed, frequency distributions of movement distance for each life-history class in each year. Our analyses of these distributions followed the advection-diffusion framework described by Turchin (1998) and Skalski \& Gilliam (2000), where advection refers to the direction of movement (up- versus downstream) and diffusion refers to variation in movement distances by individuals in the population.

\section{Intrapopulation and temporal variation in sculpin movement}

Our primary objectives were to quantify the overall degree of movement by sculpins in Shope Fork and describe intrapopulation variation in movement behaviour. First, we obtained simple estimates of mean signed (i.e. up- versus downstream) and unsigned (i.e.

(C) 2004 Blackwell Publishing Ltd, Freshwater Biology, 49, 631-645 
ignoring direction) movement distance, standard deviation of signed movement distance, and kurtosis of signed movement distance. We then used t-tests to determine if mean signed movement differed significantly from zero (i.e. to detect preferential up- or downstream movement). We also tested for normality of movement distributions using D'Agostino's test and estimated kurtosis for each size class each year (Turchin, 1998). These comparisons were made to assess the degree of leptokurtosis (sensu Skalski \& Gilliam, 2000) in movement distributions both within and among years. Skalski \& Gilliam (2000) showed that leptokurtosis of movement distributions provides a good indicator of individual level variation in movement behaviour (i.e. mobile versus sedentary individuals).

We also examined differences in the movement behaviour of sculpin size classes and differences within these classes over time. First, we used Variance-Ratio tests to compare the standard deviation of movement distributions among sculpin size classes. The same procedure was used to compare the variance in movement among years within each size class. These comparisons determined whether the amount of population diffusion differed among size classes or within size classes from year to year. Secondly, we tested for differences in movement distance among size classes and years by conducting ANOVAs on mean squared movement data (Gilliam \& Fraser, 2001). We normalised these data with logtransformations of squared data. Finally, KolmogrovSmirnov tests were used to compare cumulative frequency distributions of sculpin movement data. We made pair-wise comparisons between size classes within years and between years within size classes. These analyses examined whether the degree of sculpin movement differed among sculpin size classes or among years within a size class. After these tests were completed, we used simple regression to relate temporal changes in movement to changes in stream flow conditions and population size structure. For these analyses, we used size class-specific measures of diffusion (i.e. standard deviation of unsigned movement) as the independent variable. Because sample sizes were Iow for this analysis ( $n=3$ years), our intent was simply to identify general relationships between movement and environmental conditions.

\section{Movement and growth}

The final objective of our study was to determine the fitness consequences of movement for individual sculpins and the degree to which this varied from year to year. For this analysis, we compared the mean annual growth rate of relatively mobile ('movers') and relatively sedentary ('stayers') sculpin for each study year. Growth was quantified as the average net change in fish mass (grams) from one season to the next and then converted to a rate $\left(45 \mathrm{~g} \mathrm{day}^{-1}\right.$, where 45 days was the typical length of time between seasonal samples). We identified movers as individuals that moved more than $2 \mathrm{~m}$ between captures in subsequent seasons and stayers as individuals that moved $<2 \mathrm{~m}$ between seasonal captures. Previous analyses of sculpin behaviour indicate that movements $<2 \mathrm{~m}$ represent restricted movements by sculpins within discrete areas (i.e. 'patch use'), whereas movements greater than $2 \mathrm{~m}$ generally represent directed movements by sculpins away from one area to another (i.e. 'patch abandonment') (Petty, 1998).

We used two-way ANOvas to test the hypothesis that mean annual growth rate (response variable) was related to movement (main effect 1) and year (main effect 2). Growth for movers and stayers was calculated separately for each season and then pooled across seasons within a year to ensure sufficient sample sizes. Growth data were normally distributed. We conducted statistical analyses on each size class separately to control for ontogenetic differences in individual growth rates and because no large adults could be identified as movers in 1994.

\section{Results}

Annual variation in flow

Flow conditions in Shope Fork varied annually (Fig. 1). The study period included years of: (i) above average flow-1994 (mean daily flow $=0.305 \mathrm{~m}^{3} \mathrm{~s}^{-1}$ ), (ii) average flow 1996 (mean daily flow $=0.246 \mathrm{~m}^{3} \mathrm{~s}^{-1}$ ), and (iii) below average flow-1995 (mean daily flow = $\left.0.177 \mathrm{~m}^{3} \mathrm{~s}^{-1}\right)$. The long-term annual $(n=55$ years $)$ mean daily flow for Shope Fork is $0.243 \mathrm{~m}^{3} \mathrm{~s}^{-1}$. Kolmogrov-Smirnov tests indicated that flows differed significantly in each year of the study (1994 versus 


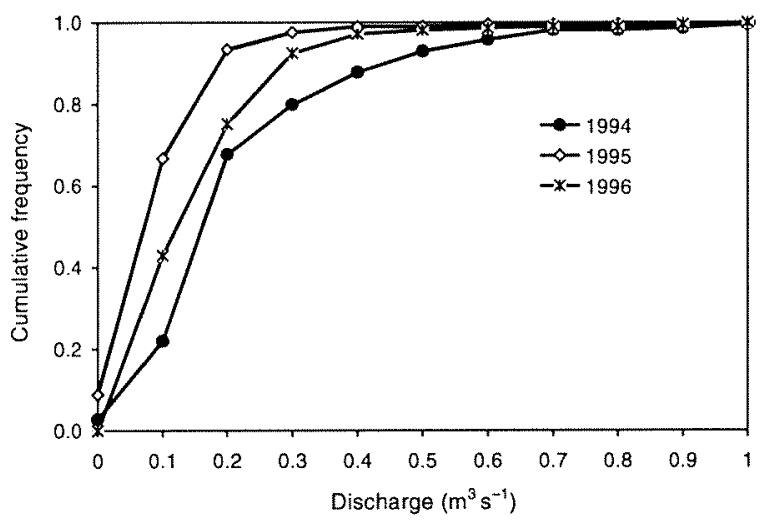

Fig. 1 Yearly variation in stream flow of Shope Fork illustrating 3 years of variable flow conditions (1994: wet year, 1995: dry year, 1996: average year). Analysis was based on mean daily flows from 1 April to 31 October of each year.

1995: $D=0.53, n=214, P<.001 ; 1994$ versus 1996 : $D=0.28, \quad n=214, \quad P<.001 ; 1995$ versus 1996: $D=0.36, n=214, P<.001)$. The critical difference in flow characteristics among years was the high frequency $(>90 \%)$ of flows less than the long-term annual mean discharge $\left(0.23 \mathrm{~m}^{3} \mathrm{~s}^{-1}\right)$ in 1995 (Fig. 1).

\section{Residency and population size}

Between late spring 1994 and autumn 1996 we marked and released a total of 604 individuals within the core $200-\mathrm{m}$ area. We recaptured 477 individuals $(79 \%)$ at least once within the $1-\mathrm{km}$ site, and these specimens were used in movement analyses. Initial analysis of mark-recapture data indicated: (i) that sculpin capture probabilities did not vary among size classes $\left(\chi^{2}=0.74\right.$, d.f. $\left.=2, P>0.5\right)$ or among years $\left(\chi^{2}=2.21\right.$, d.f. $\left.=2, P>0.1\right)$; and 2$)$ that we observed $50-65 \%$ of the sculpin population inhabiting the study site each season. Furthermore, during extensive sampling outside of the $200 \mathrm{~m}$ core site we captured only 12 emigrants, all of which were collected within $50 \mathrm{~m}$ of the up- or downstream borders of the core site.

Residency varied among size classes and juvenile residency rate was significantly lower than small and large adult residency rates in $1995(G=18.01$, d.f. $=2, P<.05)$ and $1996(G=28.48$, d.f. $=2$, $P<.05)$ but not in $1994(G=2.83$, d.f. $=2, P>.05)$ (Table 1). Furthermore, juvenile residency varied significantly among the 3 years of the study ( $G=6.57$, d.f. $=2, P<.05$ ), ranging from $55 \%$ in 1994 to $28 \%$ in 1996 (Table 1 ). In contrast, residency rates did not vary significantly among years for either small $(G=3.37$, d.f. $=2, P>.05)$ or large adults $(G=1.05$, d.f. $=2, P>.05)$ or between these two size classes. The residency rate of large adults was consistently high, ranging from $73-83 \%$ of the population (Table 1). The residency rate of small adults, although slightly lower than large adults (range from 65-78\%), also was relatively high and constant (Table 1). Despite the wide variability in juvenile residency, the rate for the entire sculpin population remained constant from year to year at $65 \%$ (Table 1 ).

\begin{tabular}{lclc}
\hline $\begin{array}{l}\text { Year/size } \\
\text { class }\end{array}$ & $\begin{array}{l}\text { Total no. } \\
\text { captured }\end{array}$ & $\begin{array}{l}\text { Residency } \\
\text { rate }\end{array}$ & $\begin{array}{l}\text { Average population } \\
\text { size }( \pm 95 \% \mathrm{CI})\end{array}$ \\
\hline 1994 & & & \\
Juveniles & 39 & $0.55^{\mathrm{a}}$ & $37(13)$ \\
Small adults & 143 & $0.65^{\mathrm{a}}$ & $99(22)$ \\
Large adults & 18 & $0.73^{\mathrm{a}}$ & $19(5)$ \\
All ages & 200 & 0.65 & $156(38)$ \\
1995 & & & $46(15)$ \\
Juveniles & 52 & $0.46^{\mathrm{a}}$ & $114(24)$ \\
Small adults & 132 & $0.78^{\mathrm{b}}$ & $28(8)$ \\
Large adults & 24 & $0.78^{\mathrm{b}}$ & $189(40)$ \\
All ages & 208 & 0.65 & $37(13)$ \\
1996 & & & $90(22)$ \\
Juveniles & 44 & $0.28^{\mathrm{a}}$ & $51(13)$ \\
Small adults & 113 & $0.75^{\mathrm{b}}$ & $178(44)$ \\
Large adults & 39 & $0.83^{\mathrm{b}}$ & \\
All ages & 196 & 0.65 & \\
\hline
\end{tabular}

Table I Summary of mottled sculpin captures in a 200-m segment of Shope Fork over a 3-year sampling period. The total number of individual sculpins of each size class captured each year is presented. Residency rate is the proportion of the population captured in at least two seasons within a year. Size classes with a different superscript letter had significantly (alpha value $=0.05$ ) different residency rates within that year. We used the Bonferroni criterion to correct for multiple comparisons. Average population size is the average of four separate seasonal estimates of population size each year 
(a)
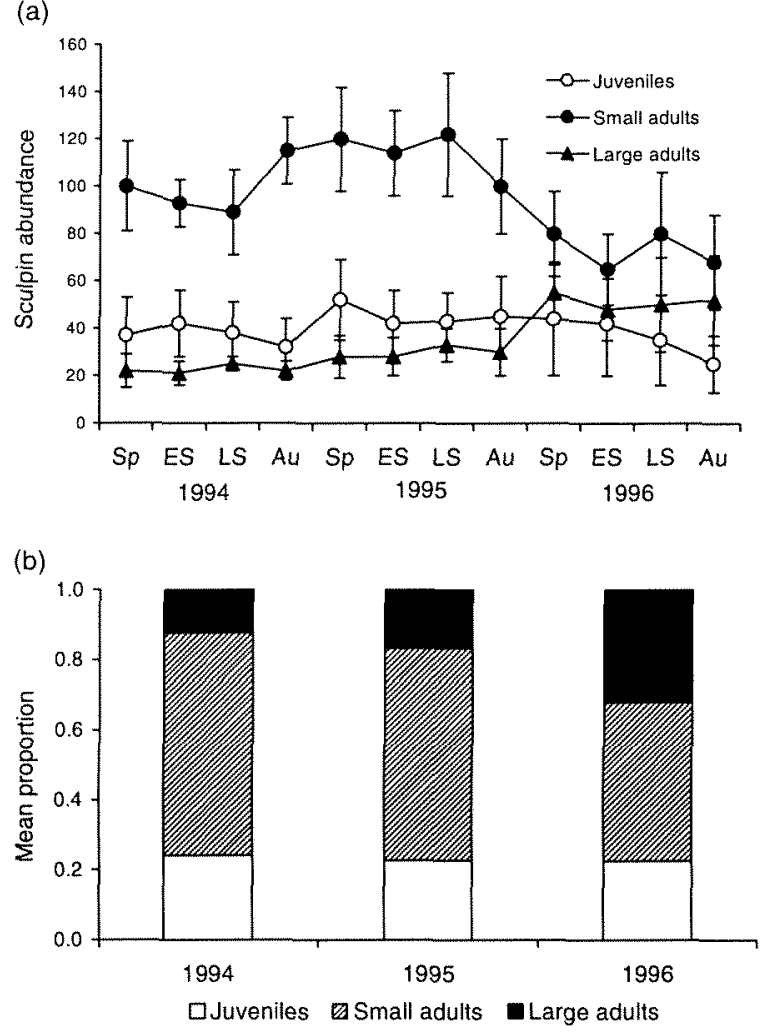

Fig. 2 Temporal variation in a mottled sculpin population inhabiting a $200-\mathrm{m}$ section of Shope Fork: (a) size $( \pm 95 \% \mathrm{CI})$ of each age class, (b) proportional contribution of each age class to the total population. Sp, spring; ES, early summer; LS, late summer; $A u$, autumn.
Mean annual population size was relatively constant during the study, and population size structure was relatively constant from 1994 to 1995 (Table 1; Fig. 2a). Small adults dominated the population and juveniles slightly outnumbered large adults in 1994 and 1995. However, the number of large adults inhabiting the study site increased significantly from an average of 19 and 28 individuals in 1994 and 1995, respectively, to 51 individuals in 1996 (Table 1; Fig. 2a). A concomitant shift in population size structure also was observed in 1996 with a significant increase in the percent composition of large adults in the population (Fig. 2b).

\section{Sculpin movement}

During our study, sculpins did not exhibit trends towards up- or downstream movement. Mean signed movement did not differ significantly from zero for any size class in any year (each case $P>0.25$ ) (Table 2; Fig. 3). Our analyses also indicated an overall low rate of movement within Shope Fork (Table 2; Fig. 3). The distance moved by individual sculpins over a 45 day period ranged from 0.1 to $165 \mathrm{~m}$. Mean unsigned movement distance ranged from $1.0 \mathrm{~m}$ (large adults in 1994) to $8.4 \mathrm{~m}$ (juveniles in 1996). Median unsigned movement distance ranged from $0.78 \mathrm{~m}$ (large adults in 1994) to $1.79 \mathrm{~m}$ (large adults in 1996) (Table 2).

Table 2 Summary statistics of mottled sculpin movement in a $1 \mathrm{~km}$ segment of Shope Fork. Signed movement refers to statistics related to up and downstream movements. Unsigned movement statistics are based on the absolute value of movement distance. Units for mean signed and unsigned movement and median unsigned movement are meters. Please see Table 3 for a summary of the results of pair-wise statistical comparisons of these values

\begin{tabular}{|c|c|c|c|c|c|c|}
\hline & \multicolumn{4}{|c|}{ Signed movement } & \multicolumn{2}{|c|}{ Unsigned movement } \\
\hline & $\mathrm{N}$ & Mean & Kurtosis & $\mathrm{SD}$ & Mean (SE) & Median \\
\hline \multicolumn{7}{|l|}{1994} \\
\hline Juveniles & 25 & 1.57 & 5.6 & 11.9 & $5.8(2.1)$ & 1.11 \\
\hline Small adults & 50 & 0.67 & 12.3 & 14.5 & $5.8(1.9)$ & 1.13 \\
\hline Large adults & 20 & 0.04 & 0.03 & 1.2 & $1.0(1.4)$ & 0.78 \\
\hline \multicolumn{7}{|l|}{1995} \\
\hline Juveniles & 29 & -0.54 & 4.5 & 3.6 & $2.2(0.5)$ & 1.28 \\
\hline Small adults & 86 & 1.38 & 37.9 & 11.9 & $4.0(1.2)$ & 1.08 \\
\hline Large adults & 38 & -0.08 & 0.9 & 2.0 & $1.6(0.2)$ & 1.14 \\
\hline \multicolumn{7}{|l|}{1996} \\
\hline Juveniles & 19 & 0.62 & 4.1 & 16.3 & $8.4(3.2)$ & 1.45 \\
\hline Small adults & 92 & 1.25 & 21.1 & 13.9 & $6.0(1.3)$ & 1.54 \\
\hline Large adults & 58 & -0.94 & 20.7 & 7.6 & $3.5(0.9)$ & 1.79 \\
\hline
\end{tabular}



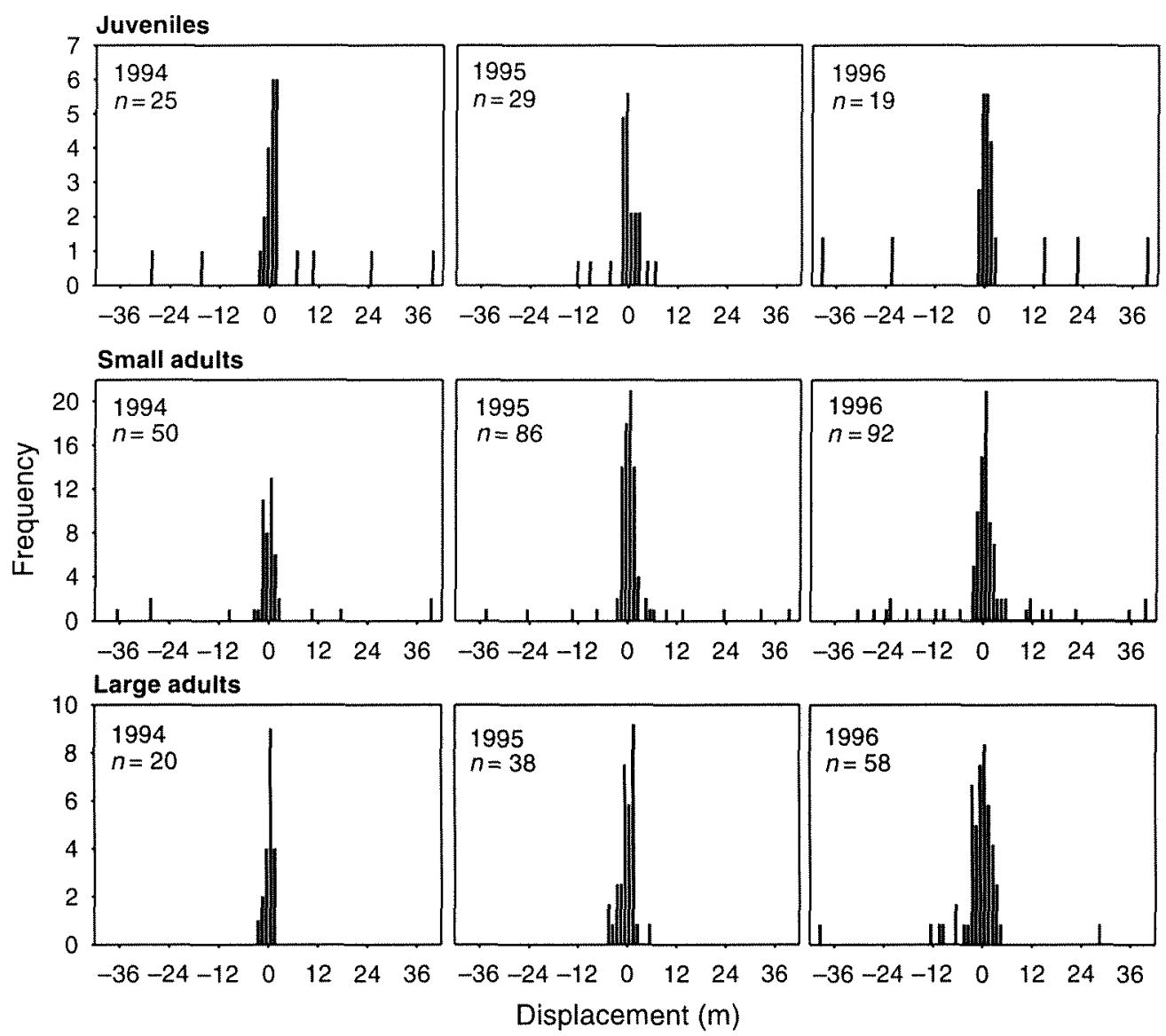

Fig. 3 Frequency distributions of movement distance by juvenile, small adult and large adult mottled sculpins residing in Shope Fork. Data from 1994 (a wet year), 1995 (a dry year), and 1996 (a year of average flow) are presented. Please refer to Tables 2 and 3 for a summary of statistics associated with each movement distribution.

\section{Intrapopulation and temporal variability in movement}

Leptokurtosis was a general feature of sculpin movement distributions (Table 2; Fig. 3). The degree of kurtosis was most extreme for small adults, ranging from 12.3 in 1994 (wet year) to 37.9 in 1995 (dry year), suggesting a high level of inter-individual variability in the movement behaviours of small adults. Kurtosis also was consistently evident in the movement distributions of juvenile sculpins ranging from 4.1 to 5.6 (Table 2). In contrast, the movement distribution of large adults generally did not exhibit kurtosis. Kurtosis was not present in the distribution of movements by large adults in 1994 and 1995 (0.03 and 0.9, respectively). In 1996, however, kurtosis for large adults increased dramatically to 20.7, indicating an increase in the level of inter-individual variability in behaviour of large adults (Table 2).
In virtually every case, size class and year significantly affected the movement of sculpins (Tables 2 and 3; Fig. 4). First, the movement behaviour of small adults was consistent across years, regardless of flow and population size structure (Tables 2 and 3; Figs. 3 \& 4). Small adults consistently exhibited both high diffusion (SD of signed movement ranged from 11.9 to 14.5 ) and high movement distances (mean unsigned movement ranged from 4.0 to $6.0 \mathrm{~m}$ ) (Tables 2 and 3). Secondly, juvenile movement was similar to that of small adults in 1994 (wet year) and 1996 (average flow), but not in 1995 (dry year) (Tables 2 and 3; Figs. 3 \& 4). Juvenile movement increased significantly with flow ISD of movement distance $=35.0 \quad$ (mean annual discharge $)+2.4$, $\left.n=3, R^{2}=0.39, P<.01\right)$ and the percentage of large adults in the population [SD of movement distance $=0.41 \quad(\% \quad$ large $\quad$ adults $)+2.6, \quad n=3$, 
Table 3 Results of pair-wise comparisons of various measures of mottled sculpin movement among size classes and among years. The Variance-Ratio test compares the standard deviation of mean signed displacement (i.e. rate of population diffusion), ANOVA compares mean unsigned displacement and represents a test of overall differences among life history classes rather than pair-wise differences, and Kolmogrov-Smirnov (K-S) compares cumulative frequency distributions of unsigned displacement

\begin{tabular}{|c|c|c|c|c|c|c|}
\hline & \multicolumn{2}{|c|}{ Variance-Ratio test } & \multicolumn{2}{|c|}{ ANOVA } & \multicolumn{2}{|l|}{$\mathrm{K}-\mathrm{S}$} \\
\hline & $F$ & d.f & $F$ & d.f. & $D$ & d.f. \\
\hline \multicolumn{7}{|c|}{ Movement among size classes } \\
\hline \multicolumn{7}{|l|}{1994} \\
\hline I versus $\mathrm{SA}$ & 1.5 & 49,24 & 2.31 & 92 & 0.5 & 5,25 \\
\hline I versus $\mathrm{LA}$ & $101.2^{* * *}$ & 24,19 & na & na & $9.25^{*}$ & 5,25 \\
\hline$S A$ versus $L A$ & $151.8^{* * *}$ & 49,19 & na & na & $6.25^{* *}$ & 5,50 \\
\hline \multicolumn{7}{|l|}{1995} \\
\hline I versus $\mathrm{SA}$ & $11.1^{* * *}$ & 85,28 & 0.36 & 150 & 2.0 & 5,29 \\
\hline I versus $\mathrm{LA}$ & 3.17 & 28,37 & na & na & 2.0 & 5,29 \\
\hline$S A$ versus $L A$ & $35.1^{* * *}$ & 85,37 & na & na & 4.0 & 5,86 \\
\hline \multicolumn{7}{|l|}{1996} \\
\hline$J$ versus $S A$ & 1.4 & 18,91 & 0.81 & 166 & 4.0 & 5,19 \\
\hline J versus LA & $4.6^{* * *}$ & 18,57 & na & na & $9.0^{* *}$ & 5,19 \\
\hline SA versus LA & $3.4^{* * *}$ & 91,57 & na & na & 4.0 & 5,93 \\
\hline \multicolumn{7}{|c|}{$\begin{array}{l}\text { Movement among years } \\
\text { Juveniles }\end{array}$} \\
\hline 94 versus 95 & $11.0^{* * *}$ & 24,28 & 2.19 & 70 & 5.0 & 5,25 \\
\hline 94 versus 96 & 1.89 & 18,24 & na & na & 4.0 & 5,25 \\
\hline 95 versus 96 & $20.7^{* * *}$ & 18,28 & na & na & $7.2^{*}$ & 5,29 \\
\hline \multicolumn{7}{|l|}{ Small adults } \\
\hline 94 versus 95 & 1.5 & 49,85 & 1.31 & 225 & 2.0 & 5,50 \\
\hline 94 versus 96 & 0.9 & 49,91 & na & na & 5.0 & 5,50 \\
\hline 95 versus 96 & 1.4 & 91,85 & na & na & 2.0 & 5,86 \\
\hline \multicolumn{7}{|l|}{ Large adults } \\
\hline 94 versus 95 & 2.9 & 37,19 & $5.86^{*}$ & 166 & 3.0 & 5,19 \\
\hline 94 versus 96 & $41.5^{* * *}$ & 57,19 & na & na & $8.5^{* *}$ & 5,19 \\
\hline 95 versus 96 & $14.3^{* * *}$ & 57,37 & na & na & $7.0^{*}$ & 5,38 \\
\hline
\end{tabular}

$* p<0.05 ; * * p<0.01 ; * * P<0.001$.

J, juveniles; SA, small adults; LA, large adults; na, not applicable.

$\left.R^{2}=0.50, P<.01\right)$. Finally, large adults exhibited extremely low movement rates in 1994 and 1995 (mean movement $=1.0$ and $1.6 \mathrm{~m}$, respectively). However, overall movement (mean movement $=3.5 \mathrm{~m}$ ) and diffusion (SD of movement $=7.6$ ) 7.6) for large adults increased significantly in 1996 (Tables 2 and 3; Figs. 3 \& 4). Consequently, we observed a significant relationship between large adult movement and the percent of large adults in the population (SD of movement distance $=0.28(\%$ large adults) $\left.+1.3, n=3, R^{2}=0.92, P<0.05\right)$.

\section{Movement and growth}

We observed significant interactive effects of movement and year (flow) on growth of juveniles, small adults and large adults (Table 4; Fig. 5). In addition, effects differed between juveniles and adults but not between large and small adults. Specifically: (i) regardless of size class, growth rate was significantly lower during 1995 (dry year) than in 1994 (wet year) and 1996 (average flow) (Table 4; Fig. 5), (ii) the growth rate of juvenile movers did not differ from that of juvenile stayers in 1994 but was significantly higher than stayers in 1995 and 1996 (Table 4; Fig. 5), and (iii) the growth rate of large and small adult movers and stayers was equal in 1994 and 1996. In 1995, however, the growth of small and large adult stayers was significantly faster than that of adult movers (Table 4; Fig. 5). Interestingly, growth versus movement patterns for adults (i.e. growth of movers < stayers) was opposite to the pattern for juveniles (i.e. growth of movers > stayers) (Fig. 5). 

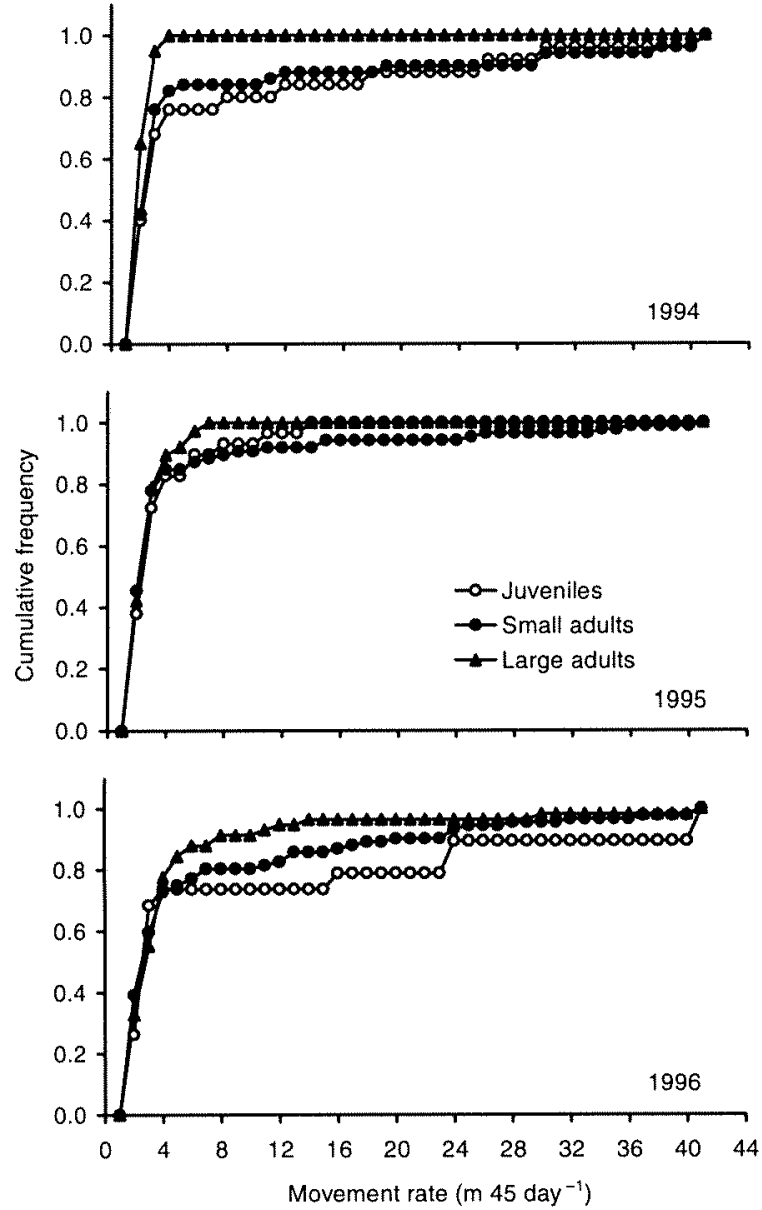

Fig. 4 Cumulative frequency distributions of mottled sculpin movement distances in Shope Fork. Distributions for juveniles, small adults, and large adults from each year are presented.

Table 4 Results of two-way ANova comparisons of individual sculpin growth rates. Analyses were run separately on juveniles, small adults and large adults. Move class refers to individual sculpin categorised as either 'movers' or 'stayers' based on movement distance

\begin{tabular}{llll}
\hline Size class/treatment & d.f. & $F$ & $P$ \\
\hline Juveniles & & & \\
$\quad$ Year & 2 & 6.96 & 0.02 \\
$\quad$ Move class & 1 & 4.64 & 0.04 \\
$\quad$ Year $\times$ move class & 2 & 12.95 & 0.003 \\
Small adults & & & \\
$\quad$ Year & 2 & 19.94 & 0.001 \\
$\quad$ Move class & 1 & 2.47 & $\mathrm{~ns}$ \\
$\quad$ Year $\times$ move class & 2 & 7.98 & 0.03 \\
Large adults & & & \\
$\quad$ Year & 1 & 4.38 & 0.05 \\
$\quad$ Move class & 1 & 2.86 & $\mathrm{~ns}$ \\
$\quad$ Year $\times$ move class & 1 & 4.64 & 0.04 \\
\hline
\end{tabular}
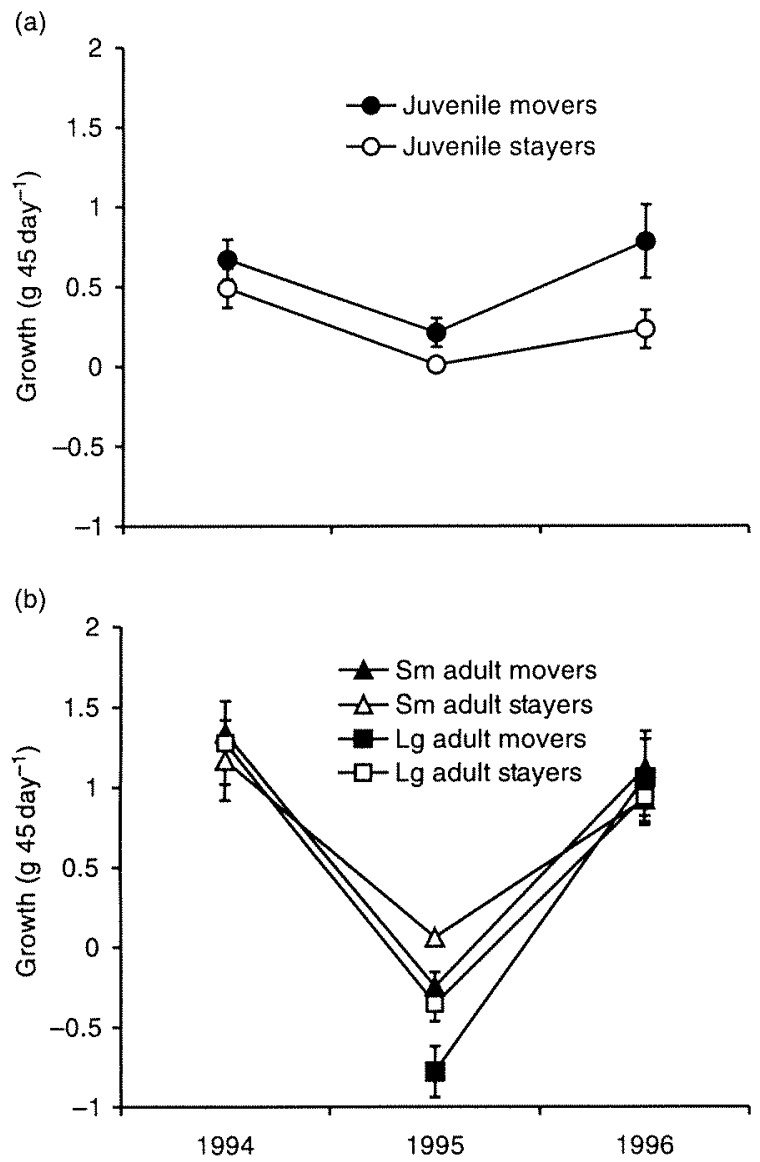

Fig. 5 Mean $( \pm \mathrm{SE})$ individual growth rate $\left(45 \mathrm{~g}^{\text {day }}{ }^{-1}\right)$ of relatively mobile (i.e. movers) and sedentary (i.e. stayers) juvenile (a) and adult (b) mottled sculpin. Missing data for large adult movers in 1994 is the result of a failure to identify any large adults that could be classified as movers in that year.

\section{Discussion}

\section{Sculpin display restricted movement}

Between 1994 and 1996, movement by sculpins in Shope Fork was very restricted. Most individuals in the population moved less than $3 \mathrm{~m}$ over a 45 day period $\left(0.07 \mathrm{~m} \mathrm{day}^{-1}\right)$. Median movement distance (pooled data) over a 45 day period was only $1.3 \mathrm{~m}$, whereas, mean movement distance over the same period was $4.4 \mathrm{~m}$. Gowan et al. (1994) argue that the poor designs of most movement studies of stream fishes produce underestimates of movement rates. Because our data were based on fish captured by hand rather than through electrofishing or seining, our estimates probably are closer to the true mobility of 
sculpins than results obtained through more disruptive sampling techniques. Furthermore, our high recapture rates $(60-80 \%$ seasonally) of sculpins are indicative of a population experiencing low turnover and low rates of movement (Gowan et al., 1994; Rodríguez, 2002). Hence, in concert with Rodríguez (2002), we suggest that it is premature to proclaim the restricted movement paradigm dead, and that it is also inappropriate to assume that stream fishes necessarily move substantial distances. Clearly, more detailed movement studies of non-salmonid stream fishes are needed.

Sculpins in Shope Fork displayed one of the lowest movement rates recorded for stream fishes. In a metaanalysis of salmonid movement studies, Rodríguez (2002) found that median movement distance ranged from 2.1 to $8300 \mathrm{~m}$, with an average distance of $28 \mathrm{~m}$. In comparison with the few non-salmonid fishes studied, sculpin movement was also low, although a minority of these studies was capable of measuring movement at spatial scales smaller than the channel unit (Hill \& Grossman, 1987b; Todd \& Rabeni, 1989; Gatz \& Adams, 1994; Freeman, 1995; Matheney \& Rabeni, 1995; Lonzarich et al., 2000; Skalski \& Gilliam, 2000; Gilliam \& Fraser, 2001). Todd \& Rabeni (1989) concluded that smallmouth bass, Micropterus dolomieu (Lacepède), exhibited restricted movements in an Ozark stream, but individual movements in their system ranged from 120 to $980 \mathrm{~m} \mathrm{day}^{-1}$ depending on water temperature. Similarly, Matheney \& Rabeni (1995) found that movements of northern hog suckers, Hypentilium nigricans (Lesueur), ranged from 276$425 \mathrm{~m} \mathrm{day}^{-1}$, and Lonzarich et al. (2000) calculated movements by central stonerollers, Campostoma

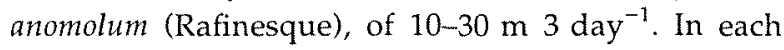
case, movement rates were one to two orders of magnitude greater than our estimates of sculpin movement, even for the few benthic fishes studied (Freeman, 1995; Matheney \& Rabeni, 1995; Lonzarich et al., 2000).

A potential reason for low movement rates by sculpin is that they are poor swimmers, who have ready access to refuge, food and reproductive habitats in Shope Fork (Grossman, Ratajczak \& Crawford, 1995; Petty, 1998; Fiumera et al., 2002). Sculpins lack a gas bladder and tend to move by hopping across the bottom rather than swimming. In addition, unlike many stream fishes, sculpins do not have to move long distances from an area used for foraging to one (c) 2004 Blackwell Publishing Ltd, Freshwater Biology, 49, 631-645 used for reproduction or refuge. For example, most of the adult males observed in Shope Fork moved $<10 \mathrm{~m}$ over the course of 3 years, a period that included multiple movements from foraging and over-wintering habitats to microhabitats used for reproduction (Petty, 1998).

The low mobility of sculpins also may have been affected by high population density. In most years, sculpin density averages one to two individuals per linear metre of stream (Freeman et al., 1988; G. D. Grossman et al., unpublished data), and Petty (1998) has shown that significant intraspecific interactions occur over patches occupied by sculpins. These factors may make it difficult for a sculpin to increase its fitness by moving, once it occupies an acceptable patch. A similar situation may affect Rivulus hartii (Boulenger) populations in Trinidad streams (Gilliam \& Fraser, 2001). This killifish occurs at very high population densities and exhibits low movement rates similar to those observed for sculpins (e.g. mean movement approximately $5.4 \mathrm{~m}$, median movement approximately $3.0 \mathrm{~m}$ over approximately 60 days, Gilliam \& Fraser, 2001). Additional studies of benthic fish are needed before general statements about the relative mobility of these species can be made.

\section{Intrapopulation variation in sculpin movement}

Despite the generally sedentary behaviour of sculpins, different size classes displayed different mobility. For example, small adults displayed a higher degree of leptokurtosis in movement distributions than did juveniles. Large adults did not exhibit kurtosis in 2 of the 3 years sampled. Skalski \& Gilliam (2000) also observed a high level of leptokurtosis in movement distributions of bluehead chubs (Nocomis leptocephalus Girard) inhabiting a North Carolina (U.S.A.) Piedmont stream. Through a combined field study and modelling approach, these authors concluded that leptokurtotic distributions were the result of pooling the movement data of two subpopulations, a relatively 'static' and a relatively 'mobile' population, each of which exhibits a normally distributed movement pattern when considered separately. By inadvertently pooling the normal distributions of two populations with different levels of dispersion, a single strongly leptokurtic distribution obtains. Consequently, Skalski \& Gilliam (2000) concluded that leptokurtosis is an indication of significant 
intrapopulation variability in movenent rates; lãge differences in the movement rates of distinct subpopulations produces high levels of leptokurtosis in the movement distributions. Fraser, Skalski \& Gilliam (2001) went on to provide experimental and field evidence of this phenomenon for $R$. hartii in Trinidadian streams.

Following the logic of previous investigators (Skalski \& Gilliam, 2000; Fraser et al., 2001; Rodríguez, 2002), the high level of leptokurtosis in movement distributions of sculpins suggests a high level of variation among individuals within each size class. Furthermore, because leptokurtosis was highest for small adults, it would appear that the highest degree of individual variation exists within this size class. However, behavioural observations of sculpins suggest that leptokurtosis of movement distribution may be the result of temporal variation in the movement behaviours of the same individual, rather than consistent variation among individuals. Analyses of the two dimensional movement patterns of adults indicate that the movement distributions of individuals are dominated by short (i.e. $<2 \mathrm{~m}$ ) moves within small, discrete areas (i.e. $<1 \mathrm{~m}^{2}$ ) separated by occasional long moves (often $>10 \mathrm{~m}$ ) (Petty, 1998). The combination of frequent, short-distance moves with occasional, long-distance moves produces a strongly leptokurtic movement distribution. This obtains although most of the individuals within the small adult size class are behaving in exactly the same way. Movement behaviours of large adults also conform to this pattern. Hence, leptokurtosis in the movement distributions of adults can be explained by temporal variability as well as inter-individual variability in movement behaviour.

Nevertheless, this explanation cannot explain leptokurtosis in movement distributions of juveniles. In contrast to adults, individual juveniles did not exhibit the consistent combination of frequent short moves and the occasional long move (Petty, 1998). Rather, juvenile sculpins tend to be either predominantly 'mobile' or 'sedentary,' much like the Rivulus studied by Fraser et al. (2001). Consequently, it is likely that the leptokurtotic movement distributions of juvenile sculpins are the result of consistent variability among individuals (sensu Skalski \& Gilliam, 2000), rather than temporal variation in individual behaviours.

The possibility that leptokurtic movement distributions are produced by temporal differences in movement behavioü within individuals, rather than by overall inter-individual differences, has important implications. The distinction between movers and stayers within a fish population has a long history in fish ecology (Gerking, 1953; Matthews, 1998), and has always involved presumed inherent differences in the behaviour of specific individuals. In contrast, it appears that the current suite of local environmental conditions determines whether an adult sculpin will be either a mover or a stayer. Hence, movement tendency is not a fixed trait in this species, but rather one that depends on the specific setting of the individual. We believe future studies of fish movement should focus on establishing whether a particular population is comprised of mobile and sedentary subpopulations or whether individuals switch between mobile or sedentary behaviour.

\section{Sculpin movement, growth and flow}

Although our study lasted only 3 years, variation in sculpin movement and growth among years and size classes yielded insights into the factors causing sculpin to move or remain sedentary. Juvenile mobility increased with increasing stream flow and increasing density of large adults. In addition, we found that mobile juveniles grew faster than sedentary ones, regardless of year. Our results for juvenile sculpins also support the findings of Skalski \& Gilliam (2000) for bluehead chub. Small, sedentary bluehead chub grew slower than more mobile individuals. Consistent with this study, our findings suggest that the movement and growth of juvenile sculpins may be simultaneously influenced by intraspecific interactions with large adults and stream flow conditions. Juvenile movers may represent 'bold' individuals (sensu Fraser et al., 2001) that are able to move around, garner scarce resources and grow fast. In contrast, juvenile stayers may represent 'shy' individuals that are trapped by larger conspecifics and suffer reduced growth, a condition exacerbated by periods of low stream flow (e.g. 1995). Experiments in which the density of large adults and stream flow are manipulated are needed to understand more fully the interactive effects of intraspecific interactions and flow conditions on juvenile sculpins.

The mobility of small and large adults differed significantly from those of juveniles. Movement by 
large and small adults was unaffected by stream flow. We also found no evidence that movement by small adults was influenced by population size structure. The mobility of large adults, however, tended to increase with their increasing density. We also found that mobile adults grew slower than sedentary adults, a pattern that was opposite of that observed for juveniles. Considering the behaviour of small and large adults together suggests that competitive interactions between adults may have a stronger effect on adult movement than flow conditions.

It is interesting that we observed differences in growth rate between adult movers and stayers only during the low flow year. At low flow, three primary factors could potentially affect sculpin movement and growth: (i) increased physiological stress because of increased temperature, (ii) a reduction in wetted area, and (iii) concentration of benthic macroinvertebrates because of decreased habitat. Increased temperature during periods of low flow undoubtedly influences sculpin growth, although, this probably affects movers and stayers equally. In fact, we observed an overall reduction in adult growth in 1995 regardless of mobility. It is more likely that growth differences between adult movers and stayers during low stream flow conditions are caused by a reduction in wetted area and the increased congregation of insects. Individuals in profitable, high-prey patches remain sedentary and grow quickly. Because of reduced habitat availability, however, movers may have difficulty finding alternative space and suffer reduced growth as a consequence.

In conclusion, the influence of stream flow and population size structure on sculpin movement and growth has important consequences for population regulation and dynamics. When the density of large adults is low, juveniles should be relatively mobile and grow quickly. Similarly, adults should grow quickly and not move. In combination, the growth and movement patterns of juveniles and adults would facilitate rapid population growth when adult density is low. In contrast, when adult population density is high, individual growth rates should decline in response to changes in the movement behaviours of juveniles and adults (i.e. reduced movement by juveniles and increased movement by adults) and result in a reduced population growth rate. Consequently, changes in sculpin mobility and growth with changes in population size and structure may provide (c) 2004 Blackwell Publishing Ltd, Freshwater Biology, 49, 631-645 an important negative feedback mechanism regulating sculpin populations.

\section{Acknowledgments}

We thank Andrew Sutherland, Bobbi Valentine, and Lee Shuff for their help with field collections. We also thank Robert Ratajczak for his assistance both in the field and laboratory. In addition, we gratefully acknowledge the years of guidance, logistical support, and access to the site provided by B. Kloeppel, W. Swank, L. Swift, B. Cunningham and the staff of the U.S. Forest Service Coweeta Hydrologic Laboratory. Earlier versions of this manuscript were greatly improved by reviews from one anonymous reviewer. Financial Support for this project was provided by grants from the U.S. Department of Agriculture McIntire-Stennis program (GEO-0047-MS), the National Science Foundation (BSR-9011661), The Daniel B. Warnell School of Forest Resources, and the University of Georgia.

\section{References}

Brown J.S. (1988) Patch use as an indicator of habitat preference, predation risk, and competition. Behavioral Ecology and Sociobiology, 22, 37-47.

Fausch K.D. \& Young M.K. (1995) Evolutionary significant units and movement of resident stream fishes: a cautionary tale. American Fisheries Society Symposium, $17,360-370$.

Fiumera A.C., Porter B.A., Grossman G.D. \& Avise J.C. (2002) Intensive genetic assessment of the mating system and reproductive success in a semi-closed population of the mottled sculpin, Cottus bairdi. Molecular Ecology, 11, 2367-2377.

Fraser D.F., Skalski G.T. \& Gilliam J.F. (2001) Explaining leptokurtic movement distributions: intrapopulation variation in boldness and exploration. American Naturalist, 158, 124-135

Freeman M.C. (1995) Movements by two small fishes in a large stream. Copeia, 1995, 361-367.

Freeman M.C. \& Stouder D.J. (1989) Intraspecific interactions influence size specific depth distribution in Cottus bairdi. Environmental Biology of Fishes, 24, 231-236.

Freeman M.C., Crawford M.K., Barrett J.C., Facey D.E., Flood M.G., Hill J., Stouder D.J. \& Grossman G.D. (1988) Fish assemblage stability in a southern Appalachian stream. Canadian Journal of Fisheries and Aquatic Sciences, 45, 1949-1958. 
Gatz, A.J. Jr. \& Adams S.M. (1994) Patterns of movement of centrarchids in two warmwater streams in eastern Tennessee. Ecology of Freshwater Fish, 3, 35-48.

Gerking S.D. (1953) Evidence for the concepts of home range and territory in stream fishes. Ecology, 34, 347365.

Gilliam J.F. \& Fraser D.F. (2001) Movement in corridors: enhancement by predation threat, disturbance, and habitat structure. Ecology, 82, 258-273.

Gowan C., Young M.K., Fausch K.D. \& Riley S.C. (1994) Restricted movement in resident stream salmonids: a paradigm lost? Canadian Journal of Fisheries and Aquatic Sciences, 51, 2626-2637.

Grossman G.D. \& Freeman M.C. (1987) Microhabitat use in a stream fish assemblage. Journal of Zoology, 212, 151-176.

Grossman G.D. \& Ratajczak R.E. (1998) Long-term patterns of microhabitat use by fishes in a southern Appalachian stream (1983-1992): effects of hydrologic period, season, and fish length. Ecology of Freshwater Fish, 7, 108-131.

Grossman G.D., Ratajczak R. Jr. \& Crawford M.C. (1995) Do rock bass (Ambloplites rupestris) induce microhabitat shifts in mottled sculpin (Cottus bairdi). Copeia, 1995, 343-353.

Grossman G.D., McDaniel K.M. \& Ratajczak R.E. (2002) Demographic characteristics of female sculpin (Cottus bairdi) in the Coweeta Creek drainage, North Carolina (U.S.A.). Environmental Biology of Fish, 63, 299-308.

Hildrew A.G. \& Giller P.S. (1994) Patchiness, species interactions and disturbance in the stream benthos. In: Aquatic Ecology: Scale, Pattern, Process (Eds P.S. Giller, A.G. Hildrew \& D.G. Raffaelli ). pp. 21-62. Blackwell Publications, Oxford.

Hill J. \& Grossman G.D. (1987a) Home range estimates for three North American stream fishes. Copeia, 1987, 376-380.

Hill J. \& Grossman G.D. (1987b) Effects of subcutaneous marking on stream fishes. Copeia, 1987, 492-495.

Hughes N.F. (1998) A model of habitat selection by driftfeeding stream salmonids at different scales. Ecology, 79, 281-294.

Hughes N.F. \& Reynolds J.B. (1994) Why do Arctic grayling (Thymallus arcticus) get bigger as you go upstream? Canadian Journal of Fisheries and Aquatic Sciences, 51, 2154-2163.

Jenkins R.E. \& Burkhead N.M. (1994) Freshwater Fishes of Virginia. American Fisheries Society, Bethesda, MD.

Kareiva P. (1990) Population dynamics in spatially complex environments: theory and data. Philosophical Transactions of the Royal Society of London, 330, 53685387.
Lee D.S., Gilbert C.R. et al. (1980) Atlas of North American Freshwater Fishes. North Carolina State Museum of Natural History, Raleigh, NC.

Lonzarich D.G., Warren M.L. Jr. \& Lonzarich M.R. (1998) Effects of habitat isolation on the recovery of fish assemblages in experimentally defaunated stream pools in Arkansas. Canadian Journal of Fisheries and Aquatic Sciences, 55, 2141-2149.

Lonzarich, D.G., Lonzarich M.R. \& Warren M.L. Jr. (2000) Effects of riffle length on the short-term movement of fishes among stream pools. Canadian Journal of Fisheries and Aquatic Sciences, 57, 1508-1514.

Matheney M.P. IV \& Rabeni C.F. (1995) Patterns of movement and habitat use by northern hog suckers in an Ozark stream. Transactions of the American Fisheries Society, 124, 886-897.

Matthews W.J. (1998) Patterns in Freshwater Fish Ecology. pp. 757.Chapman and Hall, New York, NY.

Nakano S. (1995) Individual differences in resource use, growth and emigration under the influence of a dominance hierarchy in fluvial red-spotted masu salmon in a natural habitat. Animal Ecology, 64, 7584.

Osborne L.L. \& Wiley M.J. (1992) Influence of tributary spatial position on the structure of warmwater fish communities. Canadian Journal of Fisheries and Aquatic Sciences, 49, 671-681.

Petty J.T. (1998) Mottled Sculpin in a Dynamic Landscape: Linking Environmental Heterogeneity, Individual Behaviors, and Population Regulation in a Southern Appalachian Stream. PhD dissertation. University of Georgia.

Petty J.T. \& Grossman G.D. (1996) Patch selection by sculpin (Pisces: Cottidae) in a southern Appalachian stream. Freshwater Biology, 35, 261-276.

Pollock K.H., Nichols J.D., Brownie C. \& Hines J.E. (1990) Statistical inference for capture-recapture experiments. Wildlife Monographs, 107, 1-97.

Rodríguez M.A. (2002) Restricted movement in stream fish: the paradigm is incomplete, not lost. Ecology, 83, 1-13.

Schlosser I.J. (1995) Critical landscape attributes that influence fish population dynamics in headwater streams. Hydrobiologia, 303, 71-81.

Schlosser I.J. (1998) Fish recruitment, dispersal, and trophic interactions in a heterogeous lotic environment. Oecologia, 113, 260-268.

Skalski G.T. \& Gilliam J.F. (2000) Modeling diffusive spread in a heterogeneous population: a movement study with stream fish. Ecology, 81, 1685-1700.

Snodgrass J.W. \& Meffe G.K. (1998) Influence of beavers on stream fish assemblages: effects of pond age and watershed position. Ecology, 79, 928-942. 
Stewart-Oaten A. \& Murdoch W.W. (1990) Temporal consequences of spatial density dependence. Journal of Animal Ecology, 59, 1027-1045.

Stouder D.J. (1990) Dietary Fluctuation in Stream Fishes and the Effects of Benthic Species Interactions. PhD dissertation. University of Georgia, GA.

Taylor C.M. (1997) Fish species richness and incidence patterns in isolated and connected stream pools: effects of pool volume and spatial position. Oecologia, 110, 560-566.
Tilman D. (1994) Competition and biodiversity in spatially structured habitats. Ecology, 75, 2-16.

Todd B.L. \& Rabeni C.F. (1989) Movement and habitat use by stream-dwelling smallmouth bass. Transactions of the American Fisheries Society, 118, 229-242.

Turchin P. (1998) Quantitative Analysis of Movement. Sinauer Associates, Inc., Sunderland, MA.

(Manuscript accepted 1 March 2004) 